should be worn night and day, and removed at certain times for the salke of cleanliness, for the use of frictions with manipulations directed to the maintenance of a flexible state of the articulations, otherwise the joints will become rigid, and much pain be produced in the restoration of mobility. In severe cases common splints will not suffice, you should then use irous attached to shoes.

I have mentioned that this deformity occasionally occurs in adolescence, and cases present themselves that have existed since infancy. The shortening and rigidity of the tissues on the outer side of the knee are often so unyielding that you may ineffectually devote months to the mechanical treatment. In these cases you may accelerate the cure by subcutaneous section of the biceps tendon, the inferior termination of the vastus externus, and the bands of fascia in this situation. A great improvement speedily succeeds the operation. After cicatrisation the mechanical treatment should be pursued with the same diligence as necessary without the operation. In a few weeks all resistance to straightening will be removed. Mechanical support is required for one or two years afterwards, until the articular surfaces have hecome adapted to the change in their relation, and until the debilitated muscles have acquired strength. There are numerous cases illustrative of the treatment, with or without operation, and among the out-patients you may occasionally have an opportunity of examining former patients, who come to acquaint us of the permanency of their cure. In the next lecture I shall consider rachitic curtatures and fiat-foot.

REMARKS ON THE

EFFUSION OF BLOOD

INTO THE

\section{ANTERIOR CHAMBER OF THE EYE.}

By Houmes Coote, Eaq., Surgeon to the North London Ophthalmic Institution.

InJuries to the eye are frequently followed by extravasation of blood. These may take place either between the conjunctiva and sclerotica, or in the anterior chamber, according to the situation of the vessels injured. Strictly speaking blood is effused in these cases in the posterior chamber also, but in so small a quantity as not to be generally noticed when describing these accidents. The German authors have applied (improperly, I think) the term hrmophthalmos to this condition of the eye, calling the one external, the other internal hæmophthalmos. It seems to me unadvisable to bestow a distinct appellation upon the effect merely of an accident. We have already a too ample supply of hard names in ophthalmic surgery, without unnecessarily extending the list.

I shall confine the present remarks to effusions of blood in the anterior chamber.

This is generally caused by some sudden sharp blow, or penetrating wound, or it may occur from some vessel giving way during an inflammatory attack. The accompanying drawing, taken by my friend and colleague, Mr. W. W. Cooper, from a case under his care, exhibits a large extravasation of blood flom some of the vessels of the iris, that gave way during an attack of acute inflammation of that membrane.

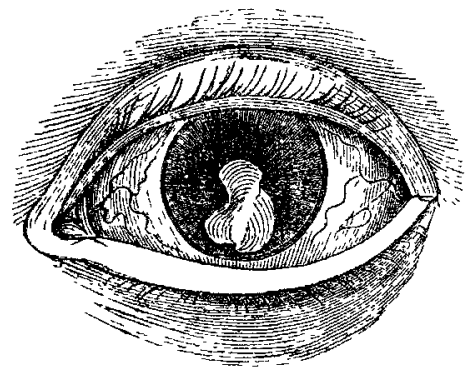

When violence is clone to the eye the blood flows immediately upon, or very shortly after, the receipt of the injury. The patient, for some seconds, is unable to open his eye, and upon doing so finds that he cannot see. The anterior chamber may be completely filled by the extravasated blood, the heavjer part of which speedily subsides to the bottom as a mass of darkish-coloured coagulum. It is by no means uncommon to find both pupil and iris completely concealed from view, when, of course, vision is lost for the time.

Formidable as this appears to be, we rarely find any evil consequences resulting, excepting such as are dependent upon the primary violence inficted upon the organ.

The anterior chamber does not very readily inflame. The membrane of the aqueous humour possesses great absorbing as well as secreting powers, and can remove a very con. siderable amount of effused fluid in a very short space of time. Many surgeons are in the habit of regarding these accidents in a serious light, and seem to imagine that they require the immediate abstraction of blood in large quantities, and the administration of mercury in such doses as rapidly to affect the system, and with no small surprise did I find that Professor Yüngken, of Vienna, in his "Treatise on Diseases of the Eye," allude to the fact of its being sometimes necessary to make an opening into the auterior chamber through the cornea, so as to evacuate the mass of blood. "Sollte die Resorption des extravasirten Blutes nicht gelingen, \&c., dann eröfrne man die Geschwulst mit der Lanzette wie einen abscess und entleere das Extravasat."-(Vid. Jüngken. Seite, 779.) Any one who followed this advice wanld 
make the discovery, that no blood would flow when such an opening was made, and surely any addition to the violence already inflicted is unjustifiable. The truth is we may content ourselves with doing little in these cases. When we are satisfied that the structure of the eye is not seriously damaged, we may rest assured that the simple extravasation of blood is an evil easily remedied. A moderate cupping or leeches should there be pain. A few doses of opening physic, attention to diet, rest, and a cold lotion, are all the measures ordinarily required. Should inflammation of any tissue subsequently arise, it must be treated in the usual way.

The habit of resorting to mercury at once in these cases is to be strongly condemued, for the simple reason that such a step is wholly unnecessary. No one ever thinks of mercurialising a patient iu whom a portion of a cataract, after solution, has slipped into the anterior chamber. On the contrary, the surgeon feels no uneasiness, but is sure that absorption will go on infinitely more quickly than would be the case were that portion of the cataract left in its normal position.

I am strongly inclined to believe that the quality attributed to mercury, of promoting absorption, has been considerably exagge rated, and that its power is confined to controlling infammatory disturbance in the smaller veseels, and thus preventing further effusion. The absorbent vessels, in their natural state, are active enough of themselves.

In the present case, however, nature decides the question as to the propriety of giving mercury. Absorption commences so rapidly after the receipt of the injury that no time is allowed for mercurial action. Within twenty-four hours a diminution of the coagulum may sometimes be remarked. Within forty-eight hours the iris may be partially brought to view again, and at the ex. piration of a week, perhaps, no trace of the injury may remain except a few streaks or stains of blood on the anterior surface of the iris.

The following case came under my care October 23,1843 :-A boy, twelve years of age, received a sharp blow upon the left eye, from a small coin that another boy was whirling round, attached to a piece of string. He could not open his eye for some time afterwards, but upou doing so he found himself blind of that eye. Pupil and iris completely hid from view ; complains of pain across the forehead. Ten leeches to the left temple. Senua draught. Cold lotion.

24 (day following) it was found that a large mass of the extravasated blood had been absorbed; the upper margin of the pupil exposed to view. At the end of a week a few dark streaks upon the anterior surface of the iris alone indicated any injury. Vision was perfect.

The following case was treated by, a friend:-W. L., fourteen years of age, whilst trying to discharge a small cannon in play, received a blow on the globe of the left eye from its recoil. The whole anterior chamber was filled with blood; pupil and iris, of course, invisible.

Nov. 28. Cupping to ten ounces immediately. A pill of calomel and jalap.

Px Chloride of mercury, a grain and a half ;

Opium, one-third of a grain. Mix, for a powder, to be taken every four hours.

29. Some pain felt about the brow; a little sickness; anterior chamber still filled with blood.

30. Iris visible in parts. Some streaks of blood upon its anterior surface. A wound of the sclerotica remarked to-day. Within a fortnight the auterior chamber was clear. The mercury was discontinued, no effect having been produced either upon the gums or upon the alimentary canal. Vision nearly perfect.

Let it not be imagined that the question whether mercury should be given or no is a slight one. Those who have been salivated feel its effects for years, and I may conclude by remarking, that of all remedies mercury is that the adiministration of which should be closely restricted just to those cases where it is imperatively called for, and to no others.

Argyle-street, Jan. 9, 1844.

\section{CASE OF COLLECTION OF F 2 CES IN CAECUM,}

AND SUBSEQUENT INFLAMMATION.

\section{To the Editor of THE LanceT.}

SIR,-The accuracy of my diagnosis and treatment in the following case having been questioned, I shall feel much obliged by your inserting it in the pages of THE Lancer :-

March 2, 1843, I was requested to see Miss Druddridge, rtat. 21, of plethoric constitution, and very sedentary habits; she had been complaining for several weeks of dull, heavy pain, extending from the groin upwards to the lumbar region, and had some difficulty in walking, inclining forwards with a peculiar limp in her gait. Bowels habitually costive, seldom being relieved more than once in two or three days. At the time of my visit her skin was hot and dry; tongue foul; pulse 130, and wiry. On examining the abdomen I found considerable distention, especially towards the right iliolumbar region, corresponding to the seat of pain, which confirmed me in the opinion $I$ had first formed of the existence of a large quantity of hardened freces in the cæcum and colon, producing irritation and inflammation of a subacute character in the parts contia 